\title{
Primary peritoneal carcinoma
}

INSERM

\section{Source}

INSERM. (1999). Orphanet: an online rare disease and orphan drug data base. Primary peritoneal carcinoma. ORPHA:168829

Primary peritoneal carcinoma (PPC) is a rare malignant tumor of the peritoneal cavity of extra-ovarian origin, clinically and histologically similar to advanced-stage serous ovarian carcinoma (see this term). 